\title{
Role of perforin in controlling B-cell hyperactivity and humoral autoimmunity
}

\author{
Andrei Shustov, ${ }^{1}$ Irina Luzina, ${ }^{1}$ Phuong Nguyen,${ }^{1}$ John C. Papadimitriou, ${ }^{2}$ \\ Barry Handwerger, ${ }^{1}$ Keith B. Elkon, ${ }^{3}$ and Charles S. Via ${ }^{1}$
}

\begin{abstract}
${ }^{1}$ Research Service, Department of Veteran Affairs Medical Center and Division of Rheumatology and Clinical Immunology, and ${ }^{2}$ Pathology Department, University of Maryland School of Medicine, Baltimore, Maryland, USA

${ }^{3}$ Hospital for Special Surgery, Weill Medical College of Cornell University, New York, New York, USA
\end{abstract}

Address correspondence to: Charles S. Via, Division of Rheumatology and Clinical Immunology, MSTF 8-34, 10 S. Pine Street, University of Maryland School of Medicine Baltimore, Maryland 21201, USA.

Phone: (410) 706-6474; Fax: (410) 706-0231; E-mail: cvia@umaryland.edu.

Received for publication November 8, 1999, and accepted in revised form July 25, 2000.

To determine the role of perforin-mediated cytotoxic T lymphocyte (CTL) effector function in immune regulation, we studied a well-characterized mouse model of graft-versus-host disease (GVHD). Induction of acute GVHD using perforin-deficient donor T cells ( $\mathrm{pfp} \rightarrow \mathrm{F} 1$ ) initially resulted in features of acute GVHD, e.g., engraftment of both donor $\mathrm{CD}^{+}$and $\mathrm{CD}^{+} \mathrm{T}$ cells, upregulation of Fas and FasL, production of antihost CTL, and secretion of both Th1 and Th2 cytokines. Despite fully functional FasL activity, pfp donor cells failed to totally eliminate host B cells, and, by 4 weeks of disease, cytokine production in $\mathrm{pfp} \rightarrow \mathrm{F} 1 \mathrm{mice}$ had polarized to a Th2 response. $\mathrm{Pfp} \rightarrow \mathrm{F} 1$ mice eventually developed features of chronic GVHD, such as increased numbers of B cells, persistence of donor CD4 T cells, autoantibody production, and lupuslike renal disease. We conclude that in the setting of B- and T-cell activation, perforin plays an important immunoregulatory role in the prevention of humoral autoimmunity through the elimination of both autoreactive $\mathrm{B}$ cells and ag-specific T cells. Moreover, an ineffective initial CTL response can evolve into a persistent antibody-mediated response and, with it, the potential for sustained humoral autoimmunity.

\section{This article may have been published online in advance of the print edition. The date of publication} is available from the JCI website, http://www.jci.org. J. Clin. Invest. 106:R39-R47 (2000).

\section{Introduction}

Cytotoxic T lymphocyte (CTL) effector mechanisms include the Fas (APO-1/CD95)/FasL, perforin/granzyme, and the slower TNF-mediated pathways (1-3). It has been suggested that the rapidly responding pathways segregate with their function such that the perforin/granzyme pathway plays a major role in viral clearance (4) and tumor surveillance (5), whereas the Fas/FasL pathway plays a pivotal role in immunoregulation and homeostasis through deletion of activated cells of the immune system (6). Recent studies, however, have questioned this dichotomy, as Fas-induced apoptosis has been shown to contribute to viral clearance $(4,7)$, and Fas-deficient (lpr) mice that were also perforin deficient had a reduced survival compared with lpr mice (8). These latter results raise the possibility that perforin may play a role in immunoregulation and homeostasis in addition to its well-documented role in viral clearance.

A well-established model of immunoregulation is the parent-into-F1 model of graft-versus-host disease (GVHD) (reviewed in ref. 9). In this model, activation of both donor $\mathrm{CD}^{+}$and $\mathrm{CD}^{+} \mathrm{T}$ cells results in acute GVHD characterized by donor antihost CTLs that eliminate activated autoreactive host B cells. In addition, activated donor T cells upregulate Fas/FasL (10) and are eliminated, presumably by activation-induced cell death (AICD), such that by 4 weeks after injection, donor cells are barely detectable (11) and lymphocyte homeostasis is restored. By contrast, in chronic GVHD, anti-host CTL activity is minimal, Fas/FasL expression on donor $\mathrm{T}$ cells is reduced, and continued activation of host B cells by donor CD4+ helper T cells occurs (10). The persistence of donor CD4 T cells coupled with the failure to eliminate self-reactive B cells results in sustained autoantibody production and immune complex glomerulonephritis (9). Of note, reagents that selectively block donor $\mathrm{CD}^{+} \mathrm{T}$ cell development into mature antihost CTLs without attenuating donor $\mathrm{CD}^{+} \mathrm{T}$ cell maturation (e.g., anti-IL-2 $\mathrm{mAb}$ ) promote the evolution of chronic GVHD (12).

We have previously shown that antihost CTLs generated in acute GVHD utilize both perforin and Fas pathways in vitro (10). To address the in vivo role of perforin in the regulation of humoral autoimmunity, perforindeficient ( $\mathrm{pfp}$ ) donor cells were used in a $\mathrm{P} \rightarrow \mathrm{F} 1$ combination that normally results in acute GVHD. Our results indicate that although pfp donor T cells can upregulate 
Fas/FasL and mature into antihost CTLs, the elimination of host $\mathrm{B}$ cells and return to homeostasis through the reduction of donor $\mathrm{T}$ cells are defective. As a result, the balance between B-cell proliferation and elimination is shifted to favor the development of a lupuslike disease.

\section{Methods}

Mice. C57BL/6J wild-type (B6wt), perforin-deficient C57BL/6-Pfp ${ }^{t m / S d z}$ (B6pfp) (4), DBA/2 and B6D2F1/J (BDF1) male mice, $6-8$ weeks of age, were purchased from The Jackson Laboratories (Bar Harbor, Maine, USA).

GVHD induction. Single-cell suspensions of viable cells (trypan blue excluding) were prepared as described previously (13) and used as a source of donor cells. Unless otherwise noted, unirradiated BDF1 mice received 50 $\times 10^{6}$ donor B6wt (acute GVHD), $50 \times 10^{6}$ B 6 pfp (pfp GVHD), or $90 \times 10^{6} \mathrm{DBA} / 2$ (chronic GVHD) spleen cells intravenously, doses that reliably induce acute and chronic GVHD (14). Control mice consisted of uninjected age- and sex-matched F1 mice.

$R T-P C R$. The coupled RT-PCR reaction was used as described previously (15). Briefly, RNase-free plastic and water were used throughout the assay. Spleen cell suspensions were homogenized in RNA-STAT-60 (TelTest, Friendswood, Texas, USA) at $1 \mathrm{~mL} / 10^{7}$ cells. RNA samples were reverse transcribed with M-MLV-RT (Life Technologies Inc., Grand Island, New York, USA). FasL specific primers were used for amplification as described elsewhere (10). To verify that equal amounts of RNA were added in each RT-PCR reaction within an experiment, primers for the housekeeping gene, hypoxanthine phosphoribosyl transferase (HPRT), were amplified in each experiment for individual mice. For each gene product, the optimum number of cycles was determined experimentally. The RT-PCR product was quantitated by densitometry for individual mice and expressed as a ratio to each respective HPRT value, and group means were calculated.

In vitro generation and measurement of cytokine production. Spleen cells from control or GVHD mice were tested for their ability to spontaneously produce the cytokines IFN- $\gamma$ and IL-10 in vitro. Spleen cells $\left(4 \times 10^{6}\right.$ per well) were cultured in 24-well plates (Corning Glass Works, Corning, New York, USA) without added stimulation in a total volume of $2 \mathrm{~mL}$ culture media as described elsewhere (13), and supernatants were harvested at 72 hours and frozen at $-20^{\circ} \mathrm{C}$ until testing. The cytokine content of each supernatant was quantitated by ELISA using anti-IFN- $\gamma$ or anti-IL-10 mAb (BD PharMingen, San Diego, California, USA). Supernatants from individual mice were tested in triplicate at four successive twofold dilutions, and individual means were calculated. OD values were converted to nanograms per milliliter or units per milliliter by comparison to a standard curve using recombinant IFN- $\gamma$ and IL-10 as standards (PharMingen).

Flow cytometry analysis and engraftment studies. Spleen cells were prepared as described elsewhere (13). After incubation with anti-murine $\mathrm{Fc}$ receptor $\mathrm{mAb}$ for 10 minutes, cells were stained with saturating concentrations of FITC-conjugated, biotin-conjugated, or PEconjugated $\mathrm{mAb}$ against CD4, CD8, B220, H-2K $\mathrm{K}^{\mathrm{d}}, \mathrm{I}-\mathrm{a}^{\mathrm{d}}$, $\mathrm{I}-\mathrm{a}^{\mathrm{b}}$, Fas (CD95), and Fas ligand purchased from BD PharMingen. Two- and three-color flow cytometry was performed using a FACScan flow cytometer (Becton Dickinson Immunocytometry Systems, San Jose, California, USA). Lymphocytes were gated by forward and side scatter, and fluorescence data were collected on 10,000 cells. Studies of donor T cells were performed on 5,000 gated cells. Donor T cells were identified as negative for $\mathrm{H}-2 \mathrm{~K}$ of the opposite parent and positive for CD4 or CD8. Host B cells were identified as B220positive, host I-a positive. Monocyte populations were excluded on the basis of forward and side scatter.

Detection of anti-host CTL activity ex vivo. Effector CTL activity was tested using freshly harvested splenocytes without an in vitro sensitization period in a 4-hour ${ }^{51} \mathrm{Cr}$ release assay as described previously (10). Splenocytes from control F1, acute GVHD, and pfp GVHD mice were tested for their ability to lyse either (a) Fas-dull P815 cell-line target $\left(\mathrm{H}-2^{\mathrm{d}}\right.$, MHC class I positive, class II negative) or (b) Fas-positive or Fas-negative L1210 cells (H-2 ${ }^{\mathrm{d}}$, MHC class I positive, class II negative). Using serial dilutions, effectors were tested in triplicate at four effector/target ratios beginning at 100:1 $\left(1.5 \times 10^{6} \mathrm{effec}-\right.$ tors and $0.015 \times 10^{6}$ targets per well). The percent lysis was calculated according to the formula: [(cpm sample - cpm spontaneous)/(cpm maximum - cpm spontaneous) $] \times 100 \%$. Results are shown as the mean per cent lysis \pm SEM at a given $\mathrm{E} / \mathrm{T}$ for each treatment group.

Serum anti-DNA antibody. Serum whole IgG and IgG isotype levels of anti-ssDNA were determined by ELISA as described previously (13). Briefly, microtiter plates were coated with heat-denatured salmon sperm DNA, blocked with $2 \%$ BSA-PBS, and incubated with twofold serial dilutions of experimental mouse sera beginning at a dilution of $1 / 40$. The plates were then incubated with alkaline phosphatase-labeled anti-mouse IgG, IgG1 or IgG2a (Southern Biotechnology Associates, Inc., Birmingham, Alabama, USA) and OD was quantitated at 405 $\mathrm{nm}$. For each experiment, pooled murine MRL/lpr sera was tested in parallel and a standard curve constructed for conversion of experimental sera OD values to units. An arbitrary value of 1,000 units was assigned to MRL/lpr sera at a dilution of 1/2,000. Serum antidsDNA was measured as described elsewhere (16) using S1 nuclease-treated calf thymus DNA.

Renal tissue. For histopathology studies, renal tissue was fixed in $10 \%$ phosphate buffered formalin, embedded in paraffin, and stained routinely with hematoxylin and eosin (H\&E). For immunohistochemistry studies, kidneys were embedded, fixed, mounted, and stained as described previously (17). Nonspecific avidin binding was blocked with avidin-biotin blocking kit (Vector Laboratories Inc., Burlingame, California, USA) and anti-Fc receptor $\mathrm{mAb}$. Sections were incubated with biotin conjugated anti-murine IgG1, IgG2a mAb (PharMingen) or horseradish peroxidase-conjugated (HRP-conjugated) 
anti-murine complement C3 (C) mAb (ICN Pharmaceuticals, Inc., Costa Mesa, California, USA) followed by alkaline phosphatase-streptavidin conjugate (Southern Biotechnology) and color developed with fast blue BB/naphthol-AS-MX phosphate (Sigma Chemical Co., St. Louis, Missouri, USA). HRP-labeled anti-murine C $\mathrm{mAb}$ were visualized using AEC substrate kit for peroxidase (Vector Laboratories).

Assessment of glomerulonephritis. All slides were blindly scored by a renal pathologist (J.C. Papadimitriou) semiquantitatively using the following scale: $0=$ normal $/$ negative; $1+=$ mild $2+=$ moderate; and $3+=$ severe. For H\&E slides, the following glomerular features were graded: mesangial hypercellularity, neutrophilic exudate, membrane thickness, crescents, and glomerular cell apoptosis. Interstitial features (venulitis and tubulitis) were also graded, and a cumulative glomerular and interstitial severity index was calculated for each individual mouse. For immunohistochemistry staining, slides were evaluated semiquantitatively, and the level of Ig or C deposition was graded using the same scale.

Urine protein measurement. Proteinuria was assessed semiquantitatively using urine dip sticks (Albustix; Bayer Diagnostics, Basingstoke, United Kingdom).

Statistical analysis. Statistical differences between groups were determined by Student's $t$ test.

Nonparametric data (glomerular score and urinary protein) was analyzed by the Mann-Whitney test.

\section{Results}

$B 6 p f p \rightarrow F 1$ mice exhibit persistent survival of host $B$ cells and autoantibody production. The data in Table 1 demonstrate that the induction of acute GVHD using B6wt donor cells (wt $\rightarrow \mathrm{F} 1$ ) is associated with a significant reduction of host $\mathrm{B}$ cells by day 14, which persists through day 28. Elimination of host B cells in $w t \rightarrow F 1$ mice is long lived and is still observed at 9-12 weeks after parental cell transfer (Figure 1). By contrast, GVHD induction using an equal or greater number of B6pfp donor T cells ( $\mathrm{pfp} \rightarrow \mathrm{F} 1$ ) is associated with elimination of fewer host B cells at days 14 and 28 after transfer compared with acute GVHD mice (Table 1). By 9 and 12 weeks after donor cell transfer, pfp $\rightarrow$ F1 mice have absolute numbers of $\mathrm{B}$ cells that are equal to or greater than those of normal F1 mice (Figure 1), indicating that impaired elimination of host B cells in $\mathrm{pfp} \rightarrow \mathrm{F} 1$ mice is a stable, long-term defect. Because host $B$ cells are eliminated early in acute GVHD mice, autoantibody production is typically transient (13)and gone by day 28 (Table 1); however, the impaired elimination of host $\mathrm{B}$ cells in $\mathrm{pfp} \rightarrow \mathrm{F} 1$ mice is associated with significantly elevated serum anti-ssDNA antibody levels at both 14 and 28 days after disease induction (Table 1), indicating the presence of activated autoreactive B cells.

Defective elimination of host $B$ cells in $p f p \rightarrow F 1$ mice is not explained by reduced donor $C D 8^{+} T$ cell engraftment. It has been previously shown that elimination of host $\mathrm{B}$ cells in this model of acute GVHD is mediated by donor anti-host $\mathrm{CD}^{+}{ }^{+}$CTLs $(14,18)$. Defective elimination of host $\mathrm{B}$ cells in $\mathrm{pfp} \rightarrow \mathrm{F} 1$ mice cannot be explained by reduced numbers of $\mathrm{CD}^{+} \mathrm{T}$ cells in the B6pfp donor inoculum as the percentage of $\mathrm{CD}^{+} \mathrm{T}$ cells in the donor inocula from five independent experiments did not differ significantly between B6wt and B6pfp mice (wt $=7.1 \pm 0.4 \%$ vs. pfp $=5.7 \% \pm 0.8 ; n=5, P=$ not significant $[\mathrm{NS}]$ ). Second, defective elimination of host $\mathrm{B}$ cells in $\mathrm{pfp} \rightarrow \mathrm{F} 1$ mice could not be corrected by either (a) adjusting the donor inocula such that equal numbers of donor $\mathrm{CD}^{+} \mathrm{T}$ cells were injected (data not shown), or (b) injecting greater numbers of pfp donor T cells (Table 1, day 14).

We previously observed that the number of donor $\mathrm{CD}^{+} \mathrm{T}$ cells engrafted is a better correlate of acute GVHD development than is the number of donor $\mathrm{CD}^{+} \mathrm{T}$ cells injected (13). Whereas the injection of greater numbers of B6pfp donor cells $\left(75 \times 10^{6} \mathrm{pfp}\right.$ vs. $50 \times 10^{6} \mathrm{wt}$ ) resulted in increased engraftment of donor $\mathrm{CD}^{+} \mathrm{T}$ cells in $\mathrm{pfp} \rightarrow \mathrm{F} 1$ compared with wt $\rightarrow \mathrm{F} 1$ mice, elimination of host $\mathrm{B}$ cells in $\mathrm{pfp} \rightarrow \mathrm{F} 1$ mice was significantly less efficient compared with wt $\rightarrow$ F1 mice (Table 1). Even the injection of twice as many pfp $(1 \times$ $\left.10^{8}\right)$ vs. wt $\left(50 \times 10^{6}\right)$ donor cells failed to eliminate host splenic B cells to levels observed in acute GVHD at two weeks after injection (wt $\rightarrow \mathrm{F} 1=1.6 \times 10^{6} \pm 0.2 \mathrm{~B}$ cells vs. $\mathrm{pfp} \rightarrow \mathrm{F} 1=20.0 \times 10^{6} \pm 3.6 \mathrm{~B}$ cells; $\left.n=5, P=0.001\right)$. Although host B cells decreased substantially by 4 weeks after transfer in $\mathrm{pfp} \rightarrow \mathrm{F} 1\left(7.1 \times 10^{6} \pm 1.9\right)$, B cell numbers were still higher than the 2 -week nadir observed in wt $\rightarrow$ F1 typical of acute GVHD $(P=0.016)$.

Defective elimination of host $B$ cells in $p f p \rightarrow F 1$ mice is not due to preferential B-cell expansion. B-cell expansion in the $\mathrm{P} \rightarrow \mathrm{F} 1$ model has been shown to be driven solely by alloreactive donor $\mathrm{CD}^{+} \mathrm{T}$ cells that provide cognate

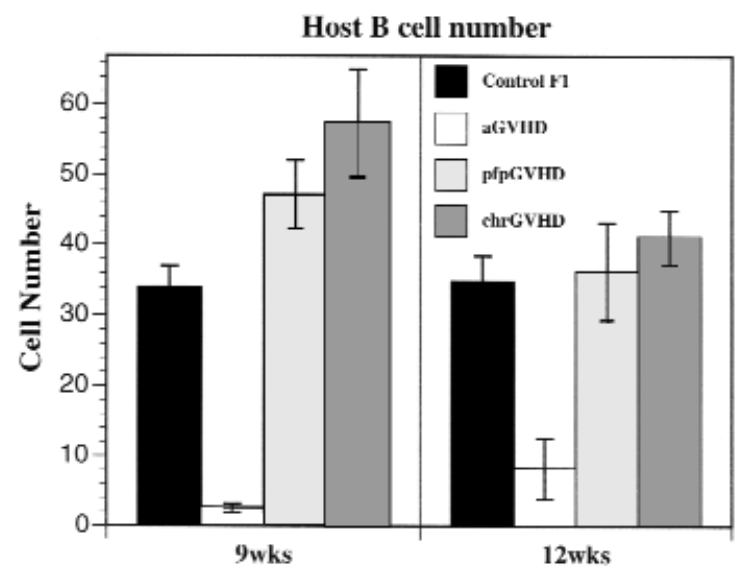

Figure 1

Long-term survival of host B cells in pfp GVHD is similar to that of chronic GVHD mice. Splenic host B cells were quantitated by flow cytometry in acute GVHD (B6wt $\rightarrow$ F1), chronic GVHD (DBA $\rightarrow \mathrm{F} 1)$, and pfp GVHD (B6pfp $\rightarrow \mathrm{F} 1)$ mice at 9 and 12 weeks after parental cell transfer. Values represent group mean cells per spleen $\times 10^{-6} \pm$ SE ( $n=4-5$ mice per group). Similar results were seen at 6 and 8 weeks after parental cell transfer. 
Table 1

Elimination of host B cells is impaired in B6pfp $\rightarrow \mathrm{F} 1$ mice compared with B6wt $\rightarrow \mathrm{F} 1$ mice (acute GVHD) and results in humoral autoimmunity

\begin{tabular}{|c|c|c|c|c|c|}
\hline & \multirow[b]{2}{*}{ Group } & \multicolumn{2}{|c|}{ Donor } & \multirow{2}{*}{$\begin{array}{l}\text { Host } \\
\text { B220+ }\end{array}$} & \multirow{2}{*}{$\begin{array}{c}\text { anti-ssDNA } \\
\text { Units }\end{array}$} \\
\hline & & $\mathrm{CD}^{+}{ }^{+}$ & $\mathrm{CD}^{+}$ & & \\
\hline \multirow[t]{2}{*}{ Day 10} & $\begin{array}{l}\text { Control F1 } \\
\text { B6wt } \rightarrow F 1 \\
\left(50 \times 10^{6}\right)\end{array}$ & $\begin{array}{c}\text { ND } \\
5.8 \pm 0.2\end{array}$ & $\begin{array}{c}\text { ND } \\
8.8 \pm 0.8\end{array}$ & $\begin{array}{l}28.3 \pm 1.9 \\
22.7 \pm 2.0\end{array}$ & $\begin{array}{l}\text { NT } \\
\text { NT }\end{array}$ \\
\hline & $\begin{array}{l}\text { B6pfp } \rightarrow \text { F1 } \\
\left(50 \times 10^{6}\right)\end{array}$ & $7.4 \pm 0.31^{\mathrm{A}}$ & $16.1 \pm 2.0^{\mathrm{A}}$ & $58.4 \pm 2.1^{\mathrm{A}}$ & NT \\
\hline \multirow[t]{2}{*}{ Day 14} & $\begin{array}{l}\text { Control F1 } \\
\text { B6wt } \rightarrow \mathrm{F} 1 \\
\left(50 \times 10^{6}\right)\end{array}$ & $\begin{array}{c}\text { ND } \\
3.1 \pm 0.5\end{array}$ & $\begin{array}{c}\text { ND } \\
4.9 \pm 1.2\end{array}$ & $\begin{array}{c}47.8 \pm 2.7 \\
8.4 \pm 3.8\end{array}$ & $\begin{array}{c}<5 \\
109.8 \pm 16.2\end{array}$ \\
\hline & $\begin{array}{l}\text { B6pfp } \rightarrow \text { F1 } \\
\left(75 \times 10^{6}\right)\end{array}$ & $3.1 \pm 1.0$ & $7.2 \pm 0.4^{\mathrm{A}}$ & $19.4 \pm 1.0^{\mathrm{A}}$ & $153.0 \pm 34^{\mathrm{A}}$ \\
\hline \multirow[t]{2}{*}{ Day 28} & $\begin{array}{l}\text { Control F1 } \\
\text { B6wt } \rightarrow \mathrm{F} 1 \\
\left(50 \times 10^{6}\right)\end{array}$ & $\begin{array}{c}\text { ND } \\
0.8 \pm 0.2\end{array}$ & $\begin{array}{c}\text { ND } \\
1.3 \pm 0.3\end{array}$ & $\begin{array}{c}34.8 \pm 1.0 \\
0.9 \pm 0.3\end{array}$ & $\begin{array}{c}8.8 \pm 4 \\
<5\end{array}$ \\
\hline & $\begin{array}{l}\text { B6pfp } \rightarrow \text { F1 } \\
\left(50 \times 10^{6}\right)\end{array}$ & $1.8 \pm 0.3^{A}$ & $0.9 \pm 0.1$ & $17.4 \pm 6.1^{\mathrm{A}}$ & $70.2 \pm 1.4^{\mathrm{A}}$ \\
\hline \multirow[t]{3}{*}{$\begin{array}{l}\text { Day } 10 \\
\text { CD8-depletec }\end{array}$} & $\begin{array}{l}\text { Control F1 } \\
\text { d }\end{array}$ & ND & ND & $46.9 \pm 5.3$ & NT \\
\hline & $\begin{array}{l}\text { CD4wt } \rightarrow \text { F1 } \\
\left(5 \times 10^{6}\right)\end{array}$ & $6.6 \pm 0.7$ & ND & $102.8 \pm 9.2$ & NT \\
\hline & $\begin{array}{l}\text { CD4pfp } \rightarrow F 1 \\
\left(5 \times 10^{6}\right)\end{array}$ & $5.0 \pm 0.5$ & ND & $115.0 \pm 12.0$ & NT \\
\hline
\end{tabular}

Acute and pfp GVHD were induced using the donor cell numbers shown in parentheses. For the $\mathrm{CD} 8$ depletion studies, $5 \times 10^{6}$ donor $\mathrm{CD} 4^{+} \mathrm{T}$ cells were injected into $\mathrm{F} 1$ mice. Splenocytes were analyzed by three-color flow cytometry at the times indicated for donor T-cell engraftment and persistence of host B cells. Values represent mean absolute number of cells $\pm \mathrm{SEM} \times 10^{-6}(n=5$ mice per group for all experiments). Anti-ssDNA antibody levels are expressed as units per milliliter (see Methods). ND, not detectable above control F1 levels; NT, not tested. AP $<0.01$, acute GVHD versus pfp GVHD.

help to host B cells $(9,19)$. To determine whether the greater number of residual host $\mathrm{B}$ cells in $\mathrm{pfp} \rightarrow \mathrm{F} 1$ mice reflects differential donor CD4-driven B-cell expansion (as opposed to differential CD8 ${ }^{+} \mathrm{T}$ cell elimination), we compared the ability of B6wt or B6pfp $\mathrm{CD}^{+} \mathrm{T}$ cells (CD8-depleted) to drive host B-cell expansion. As

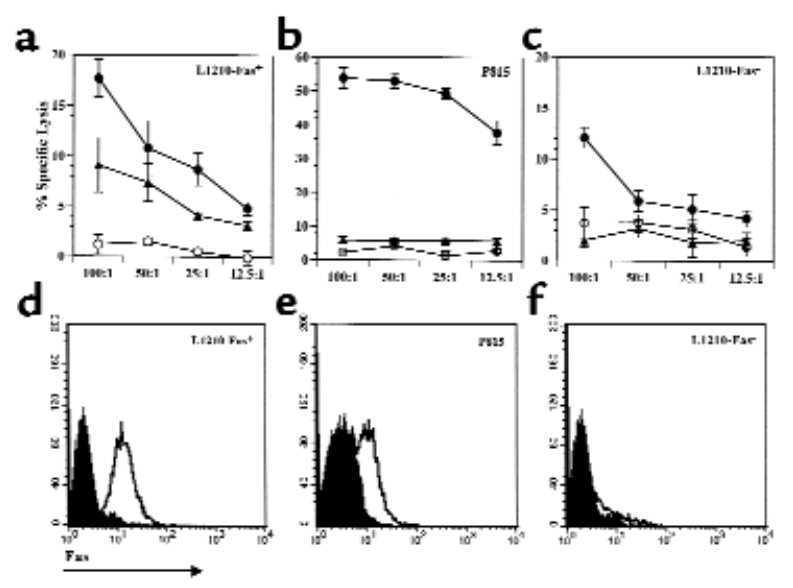

Figure 2

Splenocytes from B6pfp $\rightarrow$ F1 mice exhibit Fas-dependent antihost CTL activity. Antihost CTL activity from control BDF1 (open circles), $\mathrm{B} 6 \mathrm{wt} \rightarrow \mathrm{F} 1$ (closed circles), and B6pfp $\rightarrow \mathrm{F} 1$ (closed triangles) mice is shown for (a) L1210 Fas-positive, (b) P815 Fas-dull, and (c) L1210 Fas-negative targets at four successive $E / T$ ratios. Target expression of murine Fas is shown in $\mathbf{d}-\mathbf{f}$. Isotype-matched irrelevant Ig was used for background staining (shaded histograms). Similar results were obtained in an additional independent experiment. shown in Table 1 , the injection of $5 \times$ $10^{6} \mathrm{CD}^{+} \mathrm{T}$ cells from B6wt or B6pfp donors resulted in comparable expansion of host $\mathrm{B}$ cells $(P=\mathrm{NS})$. Thus the persistence of host $\mathrm{B}$ cells in $\mathrm{pfp} \rightarrow \mathrm{F} 1$ mice (Table 1 ) is explained by defective B-cell elimination by pfp CD8 $\mathrm{T}$ cells rather than an intrinsic effect of pfp CD4 T cells.

Fas/FasL-mediated CTL function is intact in $p f p \rightarrow F 1$ mice. We have previously reported that ex vivo antihost CTL activity in acute GVHD has both perforin- and FasL-mediated components and that Fas and FasL are upregulated on host B and donor $T$ cells, respectively, by day 10 after parental cell transfer (10). To exclude the possibility that perforin deficiency produced a secondary effect on Fas or FasL regulation, phenotypic and functional studies were performed. Flow cytometry analysis at 10 days after parental cell transfer revealed equivalent FasL upregulation for both $\mathrm{wt} \rightarrow \mathrm{F} 1$ (mean channel fluorescence $[\mathrm{mcf}]=11.2 \pm 0.4 ; n=5)$ and $\mathrm{pfp} \rightarrow \mathrm{F} 1 \quad(\mathrm{mcf}=9.7 \pm 0.5 ; n=5)$ mice compared with naive donor B6 spleen cells $(\mathrm{mcf}=6.8)$. Similarly, compared with control F1 B cells $(\mathrm{mcf}=15.1 \pm 0.9$; $n=5$ ), equivalent upregulation of Fas was observed on host $\mathrm{B}$ cells for both $\mathrm{wt} \rightarrow \mathrm{F} 1(\mathrm{mcf}=42.9 \pm 3.2 ; n=5)$ and $\mathrm{pfp} \rightarrow \mathrm{F} 1$ mice $(\mathrm{mcf}=41.1 \pm 1.6 ; n=5)$. Similar results were seen at 14 days after transfer (data not shown). RTPCR analysis of the appropriate cell subsets was concordant with these results (data not shown).

To ensure that engrafted pfp donor $\mathrm{T}$ cells were capable of mediating apoptosis through the Fas pathway, splenocytes from $\mathrm{wt} \rightarrow \mathrm{F} 1$ or $\mathrm{pfp} \rightarrow \mathrm{F} 1$ mice were tested for their ability to lyse the following $\mathrm{H} 2-\mathrm{K}^{\mathrm{d}}$ targets: (a) Fas-negative L1210 cells, (b) Fas-transfected L1210 cells, and (c) Fas-dull P815 cells (Fas expression is shown in Figure 2, d-f). As shown in Figure 2, a-c, cells from $\mathrm{wt} \rightarrow \mathrm{F} 1$ mice lysed all three targets, although lysis of Fasnegative targets was reduced compared with lysis of L1210 Fas-positive cells, consistent with the loss of Fasmediated pathway. Effectors from $\mathrm{pfp} \rightarrow \mathrm{F} 1$ mice lysed Fas-positive but not Fas-negative L1210 targets or Fasdull P815 targets, although in some experiments, significant but low-level lysis of $\mathrm{P} 815$ by $\mathrm{pfp} \rightarrow \mathrm{F} 1$ splenocytes was observed, consistent with low target cell Fas expression (data not shown). Killing of Fas-positive targets by $\mathrm{pfp} \rightarrow \mathrm{F} 1$ mice was reduced to approximately half of that of $w t \rightarrow F 1$ mice consistent with a loss of perforin-mediated CTL activity in $\mathrm{pfp} \rightarrow \mathrm{F} 1$ mice. These data indicate that the antihost CTL effectors that arise in $\mathrm{pfp} \rightarrow \mathrm{F} 1$ mice are fully functional through the Fas pathway.

Cytokine production in $p f p \rightarrow F 1$ mice initially resembles acute GVHD but evolves to resemble chronic GVHD. The initiation of acute GVHD is characterized by production 
a

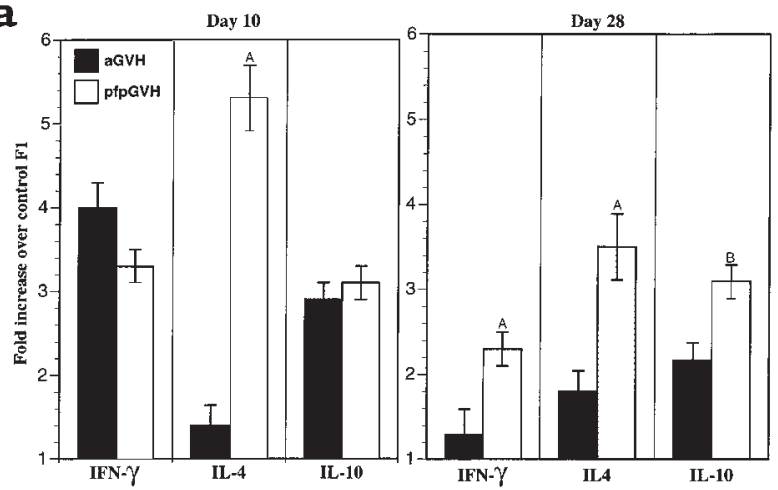

pfp GVHD vs acute GVHD b

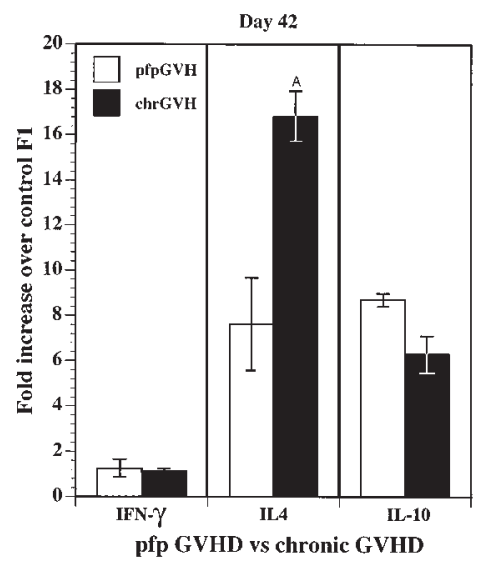

\section{Figure 3}

Kinetics of cytokine gene expression. (a) Cytokine gene expression from acute (B6wt $\rightarrow$ F1) and pfp (B6pfp $\rightarrow F 1)$ GVHD mice at 10 and 28 days after parental cell transfer. (b) Cytokine gene expression from pfp GVHD mice and chronic GVHD (DBA $\rightarrow$ F1) mice at 6 weeks after cell transfer. Results are shown as fold increase over uninjected F1 mice + SE $\left(n=4-5\right.$ mice per group). ${ }^{A} P<0.01 .{ }^{B} P<0.05$. Similar results have been seen in two additional experiments at day 10 after parental cell transfer.

of cytokines important for cell-mediated immunity (IFN- $\gamma$ ) and antibody production (IL-10, IL-4), whereas the initiation of chronic GVHD is characterized by the production of IL-4 and IL-10 and no detectable $\operatorname{IFN}-\gamma(13,20)$. To determine whether cytokine production in $\mathrm{pfP} \rightarrow \mathrm{F} 1$ mice resembles that of acute or chronic GVHD, splenocyte cytokine mRNA expression was evaluated by RT-PCR. As shown in Figure 3a, at day 10 after parental cell transfer both $\mathrm{wt} \rightarrow \mathrm{F} 1$ and $\mathrm{pfp} \rightarrow \mathrm{F} 1$ mice exhibited a three- to fourfold upregulation of IFN- $\gamma$ and an approximately threefold upregulation of IL-10, indicating that cytokine production during GVHD initiation was similar for both pfp GVHD and acute GVHD mice. Interestingly, IL-4 production was greater in pfp GVHD mice at day 10.

Although cytokine production declined in surviving acute GVHD mice by day 28, pfp GVHD mice continued to produce significant amounts of IL-4, IL-10, and IFN- $\gamma$ compared with acute GVHD mice (Figure $3 a$ ). At 6 weeks after transfer, pfp GVHD mice showed no detectable increase in IFN- $\gamma$ but a marked upregulation of IL-10 (approximately eightfold compared with controls), which was comparable to chronic, lupuslike GVHD (DBA $\rightarrow$ F1) (Figure 3b). IL-4 production was also elevated in $\mathrm{pfp} \rightarrow \mathrm{F} 1$ mice (six- to eightfold versus control F1), although the expression levels were not as high as in DBA $\rightarrow$ F1 GVHD mice. These data indicate that, although pfp GVHD mice initially had a pattern of cytokine production similar to acute GVHD, by 6 weeks, the cytokine pattern resembled that of chronic GVHD mice (increased IL-10 and IL-4 and no increased IFN- $\gamma$ ). These results were confirmed at the level of protein expression (Figure 4) at which pfp $\rightarrow \mathrm{F} 1$ mice had high spontaneous production of both IFN- $\gamma$ and IL-10 at day 7 and very low IFN- $\gamma$ with high IL-10 at 6 weeks.

Autoantibody isotypes in pfp GVHD and chronic GVHD mice. The increased levels of IFN- $\gamma$ mRNA expression during the initiation of pfp GVHD (Figures 3 and 4) are similar to that reported for acute GVHD and contrasts with the low levels of IFN- $\gamma$ mRNA typically observed in chronic GVHD mice (13). These results raise the possibility that autoantibody isotypes in pfp GVHD mice may differ from those in chronic GVHD mice and be skewed toward an IFN- $\gamma$-dependent isotype (IgG2a) rather than the IL-4-dependent isotype (IgG1). Although anti-dsDNA antibodies are frequently correlated with glomerulonephritis in human systemic lupus erythematosus (SLE), anti-dsDNA antibodies in the $\mathrm{P} \rightarrow \mathrm{F} 1$ model are typically not detected until 4 weeks of GVHD and occur in as few as $30 \%$ of GVHD mice (21). Consistent with this report, we observed in the present study that only $25 \%$ of chronic GVHD and $25 \%$ of pfp GVHD mice exhibited anti-dsDNA antibody levels above those of control mice (data not shown). However, increased anti-ssDNA antibody is a reliable marker of B-cell hyperactivity seen as early as 10 days after disease induction and occurs in nearly $100 \%$ of chronic GVHD mice (ref. 13 and unpublished observations). Because IFN- $\gamma$ is only detectable during the first 4 to 6 weeks after cell transfer in $\mathrm{pfp} \rightarrow \mathrm{F} 1$ mice, any IFN- $\gamma$ effect on isotype switching is likely to be best observed during this time period. We therefore examined anti-ssDNA antibody as an indicator of cytokineinduced isotype switching during the first 4-6 weeks of GVHD (Table 2). At each of the three time points tested, anti-ssDNA total IgG and IgG isotype production was significantly increased over control for both chronic and pfp GVHD mice. All values were greater in chronic GVHD mice compared with pfp GVHD mice; however, the relative amounts of IgG1 and IgG2a within each GVHD group were comparable and did not show pronounced skewing toward a single isotype. The number of host B cells did not differ significantly between the two groups (data not shown), thus the greater amounts of anti-ssDNA in chronic GVHD mice likely reflects the greater number of donor $\mathrm{CD}^{+} \mathrm{T}$ cells that persists in chronic GVHD compared with pfp GVHD mice (Table 2). 


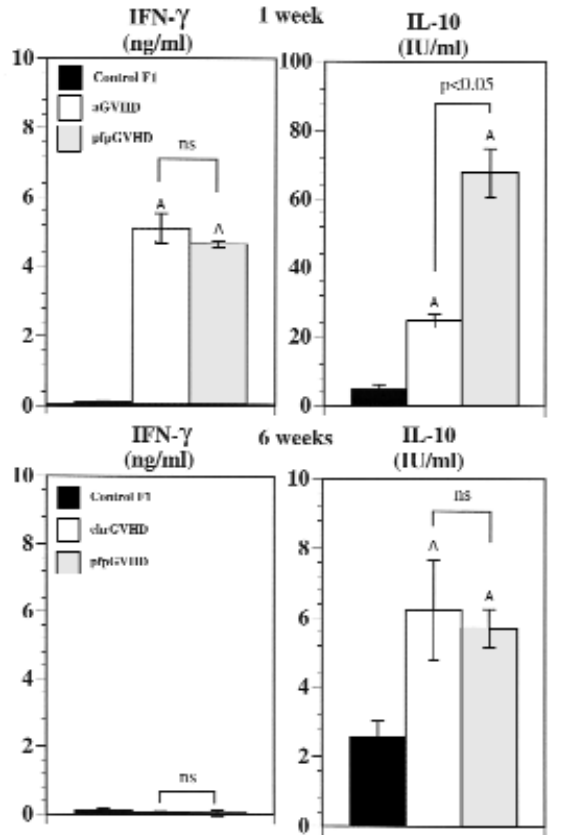

Figure 4

Kinetics of spontaneous IFN- $\gamma$ and IL-10 production in control F1 and GVHD mice. Splenocytes were tested for spontaneous in vitro IFN- $\gamma$ or IL-10 production by acute and pfp GVHD mice at 1 week of disease (upper) and by chronic and pfp GVHD mice at 6 weeks of disease (lower). Values are shown as mean $\mathrm{ng} / \mathrm{mL} \pm \mathrm{SE}$ for IFN- $\gamma$ and mean $\mathrm{U} / \mathrm{mL} \pm \mathrm{SE}$ for IL-10 at a supernatant dilution of 1:2 $(n=5$ mice per group). ${ }^{A} P<0.05$ compared with control F1 mice.

Glomerulonephritis in pfp GVHD mice. To determine whether pfp GVHD mice developed a lupuslike glomerulonephritis similar to that reported in chronic GVHD mice $(22,23)$, renal function and pathological analysis of the kidneys were performed. Increased proteinuria $(\geq 2+)$ was seen for both $\mathrm{pfp} \rightarrow \mathrm{F} 1$ and chronic GVHD mice at 4 weeks (pfp GVHD or chronic GVHD vs. control $P<0.001 ; n=8-9$ per group) and at 11 weeks (pfp GVHD or chronic GVHD vs. control $P<0.01$; $n=$ 4 per group) after disease induction. By 12 weeks, three of five chronic GVHD mice and one of five $\mathrm{pfp} \rightarrow \mathrm{F} 1$ mice had features consistent with nephrotic syndrome (ascites and/or lipemic serum). There was no spontaneous mortality in either group at this point.

Light microscopic analysis of the kidneys at 12 weeks revealed that both chronic GVHD (Figure 5g) and $\mathrm{pfp} \rightarrow \mathrm{F} 1$ (Figure 5h) mice had glomerulonephritis as evidenced by glomerular enlargement, increased glomerular lobularity, mesangial hypercellularity, and membrane thickening compared with control F1 mice (Figure 5i). These changes are similar to previous reports of glomerulonephritis in chronic GVHD (22) and were more pronounced for chronic GVHD compared with pfp GVHD (mean glomerular scores: chronic $\mathrm{GVHD}=7.3$, $\mathrm{pfp}=6.0$, normal $=0 ; P<0.05$ for chronic GVHD or pfp GVHD versus control F1). Deposition of IgG2a and C were detected in the glomeruli of both chronic GVHD (Figures 5, a and d) and pfp GVHD (Figures 5, b and e) compared with control mice. Similar results were observed for IgG1 deposition (data not shown). Consistent with higher levels of anti-ssDNA antibodies in the serum of chronic GVHD mice (Table $2)$, chronic GVHD mice also had greater glomerular deposition of $\mathrm{Ig}$ and $\mathrm{C}(2+$ to $3+)$ compared with pfp GVHD mice (1+ to $2+$ ).

Renal histopathology in acute GVHD mice was characterized mainly by interstitial changes, whereas the interstitium was typically spared in chronic GVHD and pfp GVHD mice (data not shown). Proteinuria in acute GVHD did not differ significantly from control mice $(=1+)$. Low-level proteinuria seen in control mice $(=1+)$ has been previously reported in normal mice and is not indicative of glomerular disease (23), as confirmed in Figure 5a. The foregoing data demonstrate that, although the onset of GVHD in B6pfp $\rightarrow \mathrm{F} 1$ mice resembles acute GVHD (B6wt $\rightarrow \mathrm{F} 1)$, incomplete elimination of activated autoreactive $\mathrm{B}$ cells in $\mathrm{B} 6 \mathrm{pfp} \rightarrow \mathrm{F} 1$ mice results in persistent humoral autoimmunity and conversion of disease phenotype to that of chronic GVHD.

\section{Discussion}

The major observation of this study is that perforin plays an important role in the immunoregulation of both $\mathrm{T}$ - and $\mathrm{B}$-cell-mediated responses in vivo. In the $\mathrm{P} \rightarrow \mathrm{F} 1$ model of acute GVHD, host alloantigens expressed on $\mathrm{B}$ cells become the target of donor $\mathrm{CD}^{+}$ and $\mathrm{CD}^{+} \mathrm{T}$ cells. Activation of donor $\mathrm{CD} 4^{+} \mathrm{T}$ cells results in cognate $\mathrm{T}$ cell-B cell stimulation, B-cell activation, and autoantibody production (9). Activation of donor $\mathrm{CD}^{+} \mathrm{T}$ cells leads to maturation into MHC class I-specific CTLs that eliminate host B cells, and, as a result, autoantibody production is transient (13).

Table 2

Anti-ssDNA levels are greater in chronic GVHD mice compared with pfp GVHD mice without evidence of isotype skewing

\begin{tabular}{|c|c|c|c|c|c|c|c|c|c|}
\hline & \multirow[b]{2}{*}{ Time } & \multicolumn{2}{|c|}{ Total IgG } & \multicolumn{2}{|c|}{$\operatorname{lgG} 1$} & \multicolumn{2}{|c|}{$\operatorname{lgG} 2 a$} & \multicolumn{2}{|c|}{$\mathrm{dCD}^{+}$} \\
\hline & & $\mathrm{chr}$ & $\mathrm{pfp}$ & chr & pfp & chr & pfp & chr & pfp \\
\hline Exp. 1 & 4 weeks & 252 & $76^{\mathrm{A}}$ & 271.2 & $103.5^{\mathrm{A}}$ & 148.0 & $21.5^{\mathrm{A}}$ & 3.3 & $1.1^{\mathrm{A}}$ \\
\hline Exp. 2 & 5 weeks & 172 & $52^{\mathrm{A}}$ & 168.8 & $44.2^{\mathrm{A}}$ & 144.7 & $55.3^{\mathrm{A}}$ & 7.6 & $1.5^{\mathrm{A}}$ \\
\hline Exp. 3 & 6 weeks & 672 & $200^{\mathrm{A}}$ & 387.1 & $138.8^{A}$ & 186.0 & $71.9^{\mathrm{A}}$ & 5.4 & $0.98^{A}$ \\
\hline
\end{tabular}

Chronic GVHD (DBA $\rightarrow$ F1) or pfp GVHD (B6pfp $\rightarrow$ F1) was induced and mice bled at the indicated time points. Serum anti-ssDNA IgG, IgG1, and IgG2a were determined by ELISA, and the results shown as mean arbitrary units (see Methods) for each group $(n=4-5$ mice per group). SEM were less than $10 \%$ of mean values and have been omitted. Donor $\mathrm{CD}^{+}(\mathrm{dCD} 4)$ T-cell engraftment is shown as mean cell number $\times 10^{-6}$ and was determined at 4 weeks (Exp. 1$)$, 9 weeks (Exp. 2), and 6 weeks (Exp. 3). Ig values for control mice were less than 5. AP $<0.01$. All Ig values for chronic GVHD and pfp GVHD mice were significantly greater than control $(P<0.01)$. 
Donor $\mathrm{T}$ cells expand during the first 2 weeks of disease but subsequently undergo significant depletion, presumably by AICD, during weeks 2-4 (ref. 11 and Table 1 ), and immune homeostasis is restored in the F1 animal. The present study demonstrates that in this model of in vivo cognate T-B stimulation, perforin deficiency predisposes to persistent B-cell expansion, autoantibody production, and a lupuslike disease. The mechanisms involved include defective elimination of autoreactive host $\mathrm{B}$ cells, persistence of activated donor $\mathrm{T}$ cells, and a cytokine switch from heterogeneous to a polarized Th2 response. Thus, perforin, like Fas (6) plays an important role in immunoregulation.

It should be noted that defective perforin-mediated CTL effector function does not necessarily result in autoimmunity. Perforin-deficient mice have normal life spans (4) and histologically normal immune systems (24). Although $\mathrm{CD}^{+} \mathrm{T}$ cell activation by alloantigen or virus is normal in pfp mice, CTL function in the form of viral clearance or induction of acute GVHD after bone marrow transplantation (BMT) is impaired but not totally abrogated $(25,26)$. For example, in a murine model of BMT in which recipient mice are irradiated before donor cell transfer, Levy and coworkers have shown that pfp donor cells are capable of eliminating host B cells (27) and of inducing an acute GVHD that is qualitatively similar to that seen with wild-type donor cells but is delayed on onset approxi- mately twofold (26). In contrast, in the $\mathrm{P} \rightarrow \mathrm{F} 1$ model, our results demonstrate that pfp donor cells initially induce a picture that resembles acute GVHD but by 6-8 weeks, evolves into a picture that resembles chronic lupuslike GVHD. We postulate that it is the lack of host irradiation in the $\mathrm{P} \rightarrow \mathrm{F} 1$ model that is critical for the evolution to humoral autoimmunity and chronic GVHD. Specifically, in the BMT model, irradiation renders host B cells nonfunctional. B-cell function in transplanted mice is thus a measure of donor cell repopulation. As a result, there is no possibility that humoral autoimmunity can develop in this model as a result of alloreactive donor $T$ cells, providing cognate help to host $\mathrm{B}$ cells as described in the $\mathrm{P} \rightarrow \mathrm{F} 1$ model. Moreover, our data demonstrating that $\mathrm{pfp} \rightarrow \mathrm{F} 1$ mice exhibit incomplete elimination of activated host $\mathrm{B}$ cells and persistent IL-10 production provide a framework for explaining the mechanism by which the initial acute GVHD picture in $\mathrm{pfp} \rightarrow \mathrm{F} 1$ mice evolves into humoral autoimmunity and chronic GVHD. Although IL-10 has pleiotropic effects, it has been classified as a Th2 cytokine based on its ability to serve as a costimulator of B-cell proliferation (28). It is also a major inhibitor of Th1 functions such as CTL (28) and can be produced by B cells, $\mathrm{T}$ cells, and macrophages (28) . Thus, the persisting activated autoreactive host $\mathrm{B}$ cells in Pfp GVHD mice may produce IL-10, which not only can provide a positive feedback loop leading to further
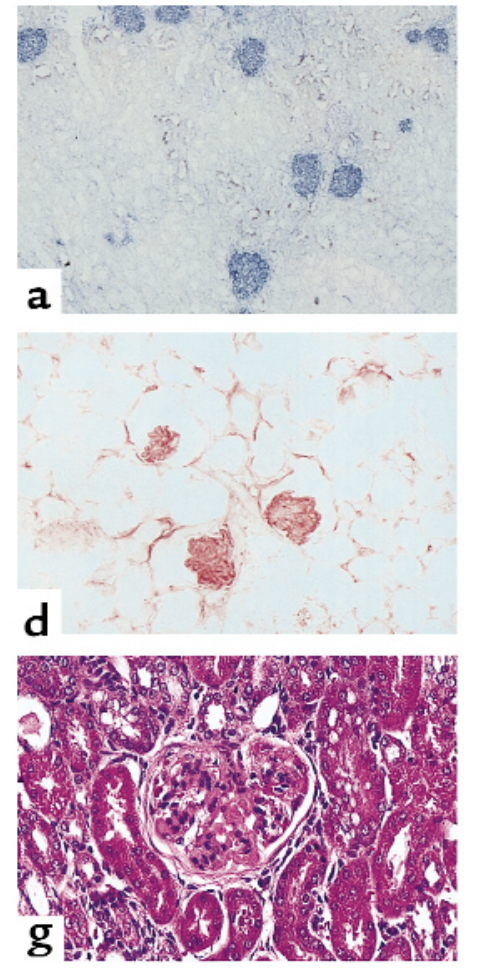
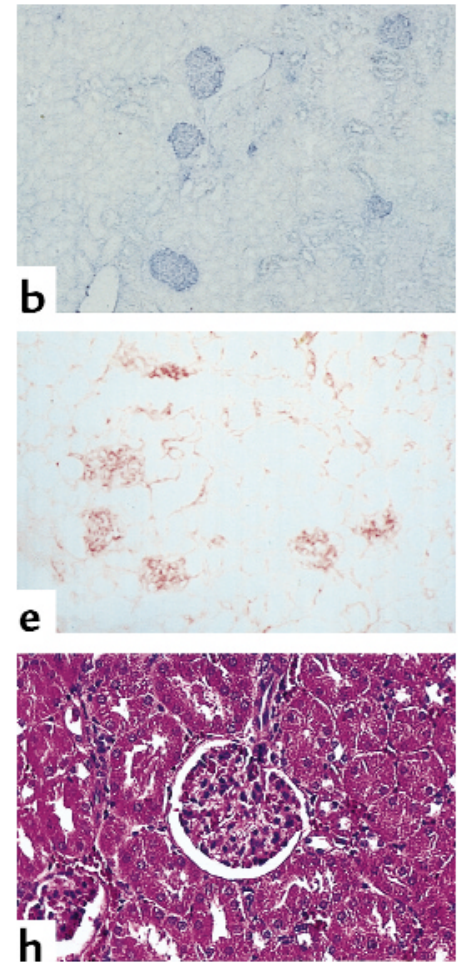

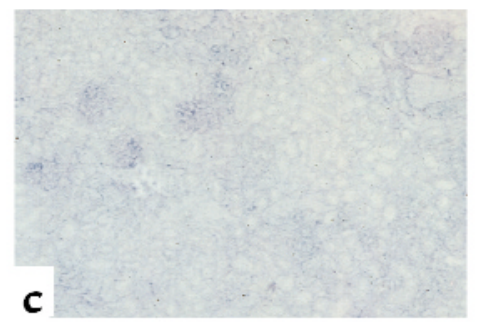

$\mathbf{C}$

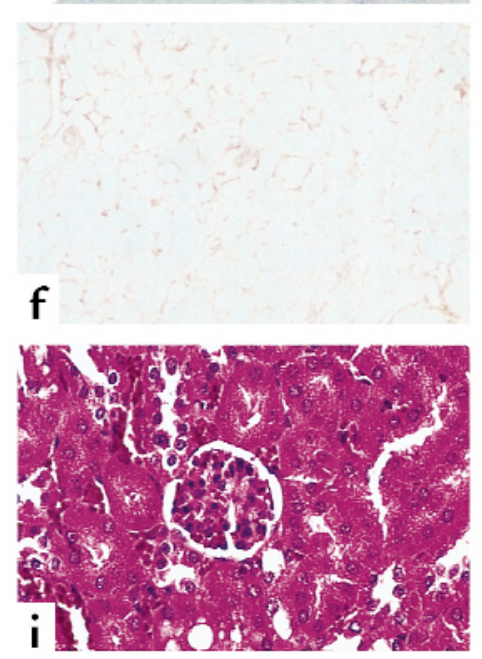

\section{Figure 5}

Kidneys from both pfp GVHD and chronic GVHD mice exhibit glomerulonephritis and deposition of IgG and C. Kidney sections from chronic GVHD (a, d, and $\mathbf{g})$, pfp GVHD ( $\mathbf{b}, \mathbf{e}$, and $\mathbf{h})$, and control F1 (c, f, and i) mice were stained with anti-murine IgG2a (a, b, and $\mathbf{c})$ and complement (d, e, and $\mathbf{f})$ or H\&E (g, h, and i) 12 weeks after donor cell transfer as described in Methods. Photographs were taken at $\times 200$. Representative results are shown from a single mouse from each group $(n=3$ per group). 
B-cell activation, humoral autoimmunity, and IL-10 production, but can also downregulate acute GVHD mechanisms by inhibiting CTL development.

Despite impaired CTL function, enhanced immune responses that could be attributed to a loss of negative regulatory activities have not been described in pfp mice as they have for fas-deficient mice (6). Whereas, in an autoimmune prone MRL strain background, perforin deficiency exacerbated disease manifestations (8), our results demonstrate that perforin plays a significant role in immunoregulation in the setting of normal Fas/FasL function. Taken together, these observations are consistent with the idea that, in addition to its role in host defense against viruses, perforin is also important in controlling autoimmunity through the deletion of activated autoreactive $B$ cells and activated ag-specific Th cells. Whether this form of immunoregulation is executed by $\mathrm{CD}^{+} \mathrm{T}$ cells and/or natural killer cells is currently under investigation.

The results obtained have implications for the pathogenesis of humoral autoimmune diseases such as SLE. Increasing evidence indicates that autoantibody production in SLE is T cell driven $(29,30)$. Paradoxically, in vitro $\mathrm{T}$-cell function and CTL generation are widely described as depressed in patients with $\operatorname{SLE}(31,32)$. It is unclear at present whether impaired CTL function is a secondary effect, e.g., due to reduced IL-2 production or to increased IL-10 production seen in $\operatorname{SLE}(33,34)$, or instead reflects an intrinsic defect in a cytotoxic effector pathway that predisposes to SLE. This question has been difficult to resolve completely in humans. An advantage of the $\mathrm{P} \rightarrow \mathrm{F} 1$ model of lupus is that mice are immunologically normal before disease induction. Thus, primary events can be separated from secondary epiphenomena. Our results clearly show that a preexisting defect in $\mathrm{CD} 8^{+} \mathrm{CTL}$ function can lead to impaired elimination of autoreactive B cells and lupuslike disease.

If the chronic GVHD model of lupus caused by defective CTL activity as shown here shares a common pathogenesis with human SLE, how could this arise? While it seems unlikely that human SLE is initiated by recognition of MHC alloantigens as in the GVHD model, the idea cannot be totally excluded in view of reports of persistent maternal-fetal microchimerism in patients with humoral autoimmunity (35). One possibility is that a B-cell tropic virus, such as Epstein-Barr virus, that infects $B$ cells regardless of the antigenic specificity through the complement receptor, CD21 (36), activates an oligoclonal population of viral specific $\mathrm{CD}^{+}$and $\mathrm{CD} 8^{+} \mathrm{T}$ cells. In either of these examples of $\mathrm{CD}^{+}{ }^{+} \mathrm{Th}$ cell stimulation by antigens expressed on $\mathrm{B}$ cells, individuals with inherited defects in one of the cytotoxic effector pathways would be unable to eliminate activated autoreactive B cells completely. As a result, activated ag-specific $\mathrm{CD} 4^{+} \mathrm{T}$ cells could persist and eventually switch from an initial CTL-mediated response to an exclusively B-cell stimulatory cytokinedriven response that would in turn promote the development of humoral autoimmunity. The permissive defect in CTL could be at the level of reduced cell-mediated immunity-promoting cytokines (TNF- $\alpha$ ), impaired effector function (perforin or fas pathways), or reduced precursor CTL frequencies, all of which have been associated with SLE $(6,14,37-39)$.

\section{Acknowledgments}

This work was supported by NIH grants AR45482 and R29 AI33882, a Department of Veterans Affairs Merit Review grant, and grants from the Maryland chapters of the Lupus Foundation and Arthritis Foundation. A. Shustov is recipient of an Engelicheff Fellowship Award from the Maryland Chapter of the Arthritis Foundation.

1. Rouvier, E., Luciani, M.F., and Golstein, P. 1993. Fas involvement in $\mathrm{Ca}(2+)$-independent $\mathrm{T}$ cell-mediated cytotoxicity. J. Exp. Med. 177:195-200

2. Millard, P.J., Henkart, M.P., Reynolds, C.W., and Henkart, P.A. 1984. Purification and properties of cytoplasmic granules from cytotoxic rat LGL tumors. J. Immunol. 132:3197-3204.

3. Clark, W.R., et al. 1995. Molecular pathways of CTL-mediated cytotoxicity. Immunol. Rev. 146:33-44.

4. Kagi, D., et al. 1994. Cytotoxicity mediated by $\mathrm{T}$ cells and natural killer cells is greatly impaired in perforin-deficient mice. Nature. 369:31-37.

5. van den Broek, M.E., et al. 1996. Decreased tumor surveillance in perforin-deficient mice. J. Exp. Med. 184:1781-1790.

6. Cohen, P.L., and Eisenberg, R.A. 1992. The lpr and gld genes in systemic autoimmunity: life and death in the Fas lane. Immunol. Today. 13:427-428.

7. Topham, D.J., Tripp, R.A., and Doherty, P.C. 1997. CD8+ T cells clear influenza virus by perforin or Fas-dependent processes. J. Immunol. 159:5197-5200.

8. Peng, S.L., Moslehi, J., Robert, M.E., and Craft, J.E. 1998. Perforin protects against autoimmunity in lupus-prone mice. J. Immunol. 160:652-660.

9. Gleichmann, E., Pals, S.T., Rolink, A.G., Radaszkiewicz, T., and Gleichmann, H. 1984. Graft-versus-host reactions: clues to the etiopathology of a spectrum of immunological diseases. Immunol. Today. 5:324-332.

10. Shustov, A., Nguyen, P., Finkelman, F.D., Elkon, K.B., and Via, C.S. 1998. Differential expression of Fas and Fas ligand in acute and chronic graftversus-host disease: up-regulation of Fas and Fas ligand requires CD8+ $\mathrm{T}$ cell activation and IFN-gamma production. J. Immunol. 161:2848-2855.

11. Hakim, F.T., Sharrow, S.O., Payne, S., and Shearer, G.M. 1991. Repopulation of host lymphohematopoietic systems by donor cells during graftversus-host reaction in unirradiated adult F1 mice injected with parental lymphocytes. J. Immunol. 146:2108-2115.

12. Via, C.S., and Finkelman, F.D. 1993. Critical role of interleukin-2 in the development of acute graft-versus-host disease. Int. Immunol. 5:565-572.

13. Rus, V., Svetic, A., Nguyen, P., Gause, W.C., and Via, C.S. 1995. Kinetics of Th1 and Th 2 cytokine production during the early course of acute and chronic murine graft-versus-host disease. Regulatory role of donor CD8+ T cells. J. Immunol. 155:2396-2406.

14. Via, C.S., Sharrow, S.O., and Shearer, G.M. 1987. Role of cytotoxic T lymphocytes in the prevention of lupus-like disease occurring in a murine model of graft-vs-host disease. J. Immunol. 139:1840-1849.

15. Svetic, A., et al. 1991. Cytokine gene expression after in vivo primary immunization with goat antibody to mouse IgD antibody. J. Immunol. 147:2391-2397.

16. Handwerger, B.S., Storrer, C.E., Wasson, C.S., Movafagh, F., and Reichlin, M. 1999. Further characterization of the autoantibody response of Palmerston North mice. J. Clin. Immunol. 19:45-57.

17. Luzina, I.G., et al. 1999. Vasculitis in the Palmerston North mouse model of lupus. Arthritis Rheum. 42:561-568.

18. Singh, J.N., Sabbadini, E., and Sehon, A.H. 1972. Cytotoxicity in graftversus-host reaction. I. Role of donor and host spleen cells. J. Exp. Med. 136:39-48.

19. Morris, S.C., Cheek, R.L., Cohen, P.L., and Eisenberg, R.A. 1990. Autoantibodies in chronic graft versus host result from cognate T-B interactions. J. Exp. Med. 171:503-517.

20. Garlisi, C.G., Pennline, K.J., Smith, S.R., Siegel, M.I., and Umland, S.P. 1993. Cytokine gene expression in mice undergoing chronic graft-versus-host disease. Mol. Immunol. 30:669-677.

21. Gleichmann, E., van Elven, E.H., and Van Der Veen, P.J.W. 1982. A systemic lupus erythematosus (SLE)-like disease in mice induced by 
abnormal T-B cell cooperation. Preferential formation of autoantibodies characteristic of SLE. Eur. J. Immunol. 12:152-159.

22. Bruijn, J.A., et al. 1988. Murine chronic graft-versus-host disease as a model for lupus nephritis. Am. J. Pathol. 130:639-641.

23. Bielschowsky, M., and D'Ath, E.F. 1971. The kidneys of NZB-B1, NZOB1, NZC-B1 and NZY-B1 mice. J. Pathol. 103:97-105.

24. Kojima, H., et al. 1994. Two distinct pathways of specific killing revealed by perforin mutant cytotoxic T lymphocytes. Immunity. 1:357-364.

25. Braun, M.Y., Lowin, B., Lars, F., Acha-Oreba, H., and Tschopp, J. 1996. Cytotoxic $\mathrm{T}$ cells deficient in both functional fas ligand and perforin show residual cytolytic activity yet lose their capacity to induce lethal acute graft-versus-host disease. J. Exp. Med. 183:657-661.

26. Baker, M.B., Altman, N.H., Podack, E.R., and Levy, R.B. 1996. The role of cell-mediated cytotoxicity in acute GVHD after MHC-matched allogeneic bone marrow transplantation in mice. J. Exp. Med. 183:2645-2656.

27. Baker, M.B., Riley, R.L., Podack, E.R., and Levy, R.B. 1997. Graft-versushost-disease-associated lymphoid hypoplasia and B cell dysfunction is dependent upon donor T cell-mediated Fas-ligand function, but not perforin function. Proc. Natl. Acad. Sci. USA. 94:1366-1371.

28. Moore, K.W., O'Garra, A., de Waal Malefyt, R., Vieira, P., and Mosmann, T.R. 1993. Interleukin-10. Annu. Rev. Immunol. 11:165-190.

29. Burlingame, R.W., Rubin, R.L., Balderas, R.S., and Theofilopoulos, A.N. 1993. Genesis and evolution of antichromatin autoantibodies in murine lupus implicates T-dependent immunization with self antigen. J. Clin. Invest. 91:1687-1696.
30. Mohan, C., Adams, S., Stanik, V., and Datta, S.K. 1993. Nucleosome: a major immunogen for pathogenic autoantibody-inducing $\mathrm{T}$ cells of lupus. J. Exp. Med. 177:1367-1381.

31. Tsokos, G.C., and Balow, J.E. 1981. Cytotoxic responses to alloantigens in systemic lupus erythematosus. J. Clin. Immunol. 1:208-216.

32. Stohl, W. 1995. Impaired polyclonal T cell cytolytic activity: a possible risk factor for systemic lupus erythematosus. Arthritis Rheum. 38:506-516

33. Tsokos, G.C. 1992. Lymphocyte abnormalities in human lupus. Clin. Immunol. Immunopathol. 63:7-9.

34. Georgescu, L., Vakkalanka, R.K., Elkon, K.B., and Crow, M.K. 1997. Interleukin-10 promotes activation-induced cell death of SLE lymphocytes mediated by Fas ligand. J. Clin. Invest. 100:2622-2633.

35. Nelson, J.L. 1998. Microchimerism and autoimmune disease. N. Engl. J. Med. 338:1224-1225.

36. James, J.A., et al. 1997. An increased prevalence of Epstein-Barr virus infection in young patients suggests a possible etiology for systemic lupus erythematosus. J. Clin. Invest. 100:3019-3026.

37. Horwitz, D.A., and Jacob, C.O. 1994. The cytokine network in the pathogenesis of systemic lupus erythematosus and possible therapeutic implications. Springer Semin. Immunopathol. 16:181-200.

38. Stohl, W., et al. 1997. Impaired nonrestricted cytolytic activity in systemic lupus erythematosus. Arthritis Rheum. 40:1130-1137.

39. Jacob, C.O., and McDevitt, H.O. 1988. Tumour necrosis factor-alpha in murine autoimmune 'lupus' nephritis. Nature. 331:356-358. 